\title{
Developing the Mechanical Engineering Curriculum in China for the Needs of National Manufacturing Development Plan
}

\author{
Handai Liu ${ }^{1, ~ a ~, ~ W e n w e i ~ Z h u a n g ~}{ }^{1, b, *}$, Keyi Zhang, c, and Chongjun Zhou ${ }^{2, d}$ \\ ${ }^{1}$ Department of Mechanical Engineering, East China University of Technology, Guanglan Street, Nanchang, \\ China \\ ${ }^{2}$ Jiangxi School of General Technology Engineering, Yunshan Street, Jiujiang, China \\ a liuhandaihfut@126.com, b472620187@qq.com, ${ }^{\mathrm{c}}$ 375897526@qq.com, ${ }^{\mathrm{d}}$ 23942309@qq.com
}

Keywords: curriculum development, comparative education, mechanical engineering.

\begin{abstract}
In twenty-first Century, many countries have formulated relevant industrial development strategies to improve the competitiveness of the country's manufacturing industry. The Made in China 2025 strategy which is in combination with the national conditions has been established in China under the provisions of relevant industrial development strategies. In order to make the mechanical engineering talents trained by Chinese colleges and universities meet the needs of the national manufacturing and development strategy better, it is urgent to develop mechanical engineering curriculum of most Universities in China. Engineering Education in western developed countries has been in the forefront of the world. The reform of mechanical engineering major in Chinese colleges and universities can gain a reliable reference through the comparison with the curriculum system of mechanical engineering in western countries, and it also helps to improve the international standards and competitiveness of mechanical engineering specialty of China. Secondly, based on China's actual situation and the new requirements of the current national manufacturing strategy, the reform of China's mechanical engineering curriculum would be more practical. The above curriculum system reform method shall be a good reference for the reform of the curriculum system in other developing countries.
\end{abstract}

\section{Introduction}

In recent years, intelligent manufacturing technologies such as big data, cloud computing, Internet of things, intelligent robots, 3D printing and digital manufacturing technology, develop rapidly, therefore, the development concept and mode of traditional manufacturing industry face a subversive, revolutionary impact and challenge. The next decade will be the transition period of integration between industrialization and information age [1]. Many countries have formulated the national development strategy centered on revitalizing manufacturing industry to seize the commanding heights of the future industrial economic competition. In 2009, the United States made the advanced manufacturing national development strategy, Britain formulated the 2050 strategy of British industry, industrial 4 strategy had been put forward in Germany, and Japan formulated the manufacturing industry white paper. In recent years, China is facing the severe challenge of global manufacturing industry, and China's manufacturing industry has no time to delay in structural adjustment, transformation and upgrading, and quality improvement [1]. China has formulated the Made in China 2025 strategy in light of its national conditions. According to the study of Chinese researchers, the training of engineering talents in China cannot meet the new requirement of Made in China 2025 strategy [2].

As a typical Chinese College of science and technology, East China University of Technology (hereinafter referred to as "ECUT") enrols more than 200 freshmen in mechanical engineering (hereinafter referred to as "ME") major each year, and has trained a large number of undergraduate applied graduates. The training scheme and mode of ME major of ECUT are in line with most of the common engineering colleges and universities in China, and the engineers and technicians trained have the problem of irrational structure and low international standard rate [2]. This paper 
introduces and implements reference methods to reform the ME curriculum system for improving the quality of ME graduates trained by ECUT and meeting the technical talents needs of Made in China 2025 strategy in the new period of China. Firstly, the ME curricula of ECUT and Athlone Institute of Technology of Ireland (hereinafter referred to as "AIT") are compared and analyzed. And then, according to the research results of the knowledge and skills needed for future ME of American Society of Mechanical Engineers (ASME) and the new demand of Made in China 2025, the reform and exploration of the ME curriculum system of ECUT has carried out. In a sense, this reform and exploration does not only provide suggestions for the course setting and optimization of the ME major in the applied science and Engineering colleges and universities in China, but also to some developing ME major in other developing country worldwide.

\section{Knowledge and Skills of ME Needed for New ME Talents}

Made in China 2025 proposes to speed up the deep integration of the new generation of information technology and manufacturing industry, with intelligent manufacturing as the breakthrough and the main direction [2]. Made in China 2025 strategy involves many new technologies, such as artificial intelligence, industrial Internet, industrial cloud computing, industrial large data, industrial robot, 3D printing, automation, industrial network security, virtual reality and many other new technology fields [3]. Currently, the teaching content of ME education in Colleges and universities in China is far from the needs of a new era of ME and technical personnel. Meanwhile, upgrading the coverage of the curriculum system of $\mathrm{ME}$ and breaking barrier between ME subject and computer science, material discipline, automatic control, industrial internetworking, intelligent manufacturing and management information system [4] should be regarded as the necessity.

In the study of the reform of the course content of the ME specialty, Li Tuoyu indicates that the new manufacturing industry would be no longer the traditional sense of the technology and economic process using modern machinery and modern management to carry out manufacturing production, but intelligent manufacturing based on the intelligent equipment of the information physical system, the new producing mode of intelligent manufacturing, the new industry form and the new development model,he also proposes to increase the content of sensing testing technology, computer application technology, automatic control and information technology, optimization design technology, engineering economy and project management[1].

At present, the curriculum system of ME in China has basically met the needs of automation manufacturing (called as industrial 3.0), but is still not enough for the needs of "industrial 4", and many core content of "industrial 4" is not fully embodied in the course setting [5]. Han Fenglin put forward the following suggestions for the typical ME curriculum system of China by comparing the talents demand of "industrial 4". Firstly, take the importance of network technology as manufacturing and automation technologies. Secondly, increase the content of intelligent perception and control technology. Thirdly, make the importance of management methods and information in ME curriculum system clearly to lay the foundation for training compound talents [5].

In order to identify the knowledge and skills needed for the global competitiveness of me graduates in the next decade and to provide recommendations for the curriculum reform of $\mathrm{ME}$ education, the American Society of Mechanical Engineers (ASME) established a working group on Engineering Education in July 2011. The working group conducted extensive research on over 1470 leading and early professional engineers as representatives and scholars in the machinery industry [6]. The chief engineers believe that the main disadvantaged aspects of early professional engineers contain equipment operation practice ability, communication ability, engineering code and standard and system engineering view, while early professional engineers thought their own weaknesses were engineering code and standard, equipment operation practice ability, project management, foreign languages, business, economics, interpersonal skills, systems engineering, and bionano information. The research results of the ASME show that communication, basic engineering theory, nondestructive testing technology, energy, nanotechnology, computer aided design, finite element analysis, computational fluid mechanics, 3D modeling software, motion analysis and simulation, 
computer programming and application, engineering computing software, data analysis and classics Economic and commercial, production quality management specification, project management, six sigma, life cycle analysis, ISO certification, engineering code and standard, quality assurance requirements of nuclear facilities and virtual reality are the most necessary knowledge and skills of mechanical engineers in the next 10 years [7].

In summary, according to the study results of Made in China 2025 strategy and the analysis and research results of relevant researchers, the automation technology, computer application technology, network technology, robot technology, 3D printing and sensing inspection, measuring technology, production quality management, project management and information technology, economy and commerce, engineering code and standard, finite element analysis, computational fluid mechanics, energy, advanced materials, nanotechnology and virtual reality technology should be added or integrated into the ME curriculum system of typical colleges and universities in China in the exploration of the curriculum reform of ME curriculum in China.

\section{The Comparison of ME Curriculum between AIT and ECUT}

Ireland's education has been widely recognized internationally, Ireland is also an initial member of the Washington Accord. Many comparative studies had been researched on high education between China and western countries like the United States, Australia and the UK, but few comparative studies between Chinese and Ireland could be seen. In order to promote the convergence of ME curriculum between ECUT and AIT, and to better manage the " $3+1$ cooperation project” between AIT and ECUT, the ME curriculum between AIT and ECUT are compared and analyzed here.

The duration for bachelor's degree in Ireland is generally three years, and the honor bachelor's degree continues four years. By contrasting the curriculum between AIT and ECUT, the undergraduate course of honor degree in Ireland is similar to the undergraduate course in China. Therefore, this article compares AIT and ECUT's four year ME undergraduate curriculum systems. Due to the particularity of undergraduates training goal of China, the ECUT ME curriculum system includes comprehensive educational courses accounting for 34 credits, such as humanities, history, ideological and moral law, Marx theory, military theory, sports and so on. AIT does not have the above related courses. And those above courses are the comprehensive needs of the development of China and cannot be changed in the short term.

The comparison of ME curriculum between AIT and ECUT has been shown in table 1 which excludes comprehensive educational courses mentioned above. The left column of Table 1 contains all the courses for the honor bachelor's degree in ME of AIT, with a total of 40 courses, each of which contains 5 credits per semester. Therefore, the honor bachelor's degree in ME for AIT requires 240 credits. The right part of Table 1 shows ECUT's undergraduate course in ME. The ME undergraduate students of ECUT need to receive 205 credits to grant a bachelor's degree in ME. In Table 1, the courses in ME are summarized into 14 modules based on the knowledge system. Among them, the modules 1 to 5 are mainly related to college mathematics, college Physics, mechanical principles and design, theoretical mechanics, material mechanics, mechanical drawing and CAD, engineering training, hydraulic instruments and measuring tools and so on, and the difference of the above between AIT and ECUT is very small. The course module 6 is about communication, language and computer applications. ECUT contains English and Keil \& C programming courses in this module, and these two aspects are important to improve the international competitiveness and programming ability of graduates. Module 7 mainly includes machining technology and process, mechanical CAD and CAM, and mold design. In this module, the ECUT course has enhanced the numerical control technology and programming and computer aided manufacturing process, but there are not a few repeating parts between curriculums and occupied much teaching time. So it needs to be reduced and optimized. 
Table 1 Comparison of the undergraduate me curriculum between AIT and ECUT

\begin{tabular}{|c|c|c|}
\hline & AIT COURSES & ECUT COURSES \\
\hline 1 & Mathematics (1\& 2.1\& 2.2\& 3) & $\begin{array}{l}\text { Advanced Mathematics(A I\&A II), Linear Algebra, } \\
\text { Probability Theory and Mathematical Statistics }\end{array}$ \\
\hline 2 & Engineering Science & $\begin{array}{l}\text { College Physics(B I), Physics Experiments (B I), } \\
\text { College Physics(B II), Physics Experiments (B II) }\end{array}$ \\
\hline 3 & $\begin{array}{l}\text { Mechanics(1\&2.1\&2.2) } \\
\text { Mechanical Systems Design } \\
\text { Systems Design \&Vibrations3 } \\
\text { System Dynamics \& Vibrations4 }\end{array}$ & $\begin{array}{l}\text { Theoretical Mechanics, Material Mechanics (A), } \\
\text { Principle of Mechanics, Machine Design, } \\
\text { Project of Machine Theory, } \\
\text { Project of Machine Design }\end{array}$ \\
\hline 4 & $\begin{array}{l}\text { Engineering Workshop Drawing \&CAD } 1 \\
\text { Engineering Practices \& CAD } 2\end{array}$ & $\begin{array}{l}\text { Engineering Practice, Numerical Control Practices, } \\
\text { Mechanical Drawing(I), Mechanical Drawing(II), } \\
\text { Acquaintanceship Practice, Production Practice, } \\
\text { Fundament of Exchangeability and Measurement }\end{array}$ \\
\hline 5 & Instrumentation & $\begin{array}{l}\text { Modern Testing Technology, } \\
\text { Hydraulic Transmission and Control }\end{array}$ \\
\hline 6 & $\begin{array}{l}\text { Communications \&Computer } \\
\text { Applications }\end{array}$ & $\begin{array}{l}\text { Practical Writing, Reading Report, } \\
\text { Mechanical Engineering English(E), } \\
\text { Fundamentals of College Computer, } \\
\text { College English(I \&II \&III \&Iv), } \\
\text { Keil \& C Programming Language\& Design }\end{array}$ \\
\hline 7 & $\begin{array}{l}\text { Process Technology and Design, } \\
\text { Processes \& Operations Management, } \\
\text { Polymer Processing \&Mould Design }\end{array}$ & $\begin{array}{l}\text { Fundamental Manufacturing Technology, } \\
\text { Project of Manufacturing Processes, } \\
\text { Numerical Control Technology, } \\
\text { CNC Programming, } \\
\text { Manufacturing Processing and Fixture (E), } \\
\text { Computer Aided Processing Design (E), } \\
\text { CAD and Manufacturing Technology (E), } \\
\text { Mould Design (E) }\end{array}$ \\
\hline 8 & $\begin{array}{l}\text { Control \& Power Technology, } \\
\text { Control \& Automation (3.1\&3.2), } \\
\text { Electrical Power Systems \&Machines, } \\
\text { Industrial Control, } \\
\text { Manufacturing Automation, }\end{array}$ & $\begin{array}{l}\text { Electrical \& Electronic Technology (I-II), } \\
\text { Experiments of Electronics \&Electronics, } \\
\text { Microcomputer and Interface Technology, } \\
\text { Fundament of Engineering Control, } \\
\text { Electrical Motor and Drive (E) }\end{array}$ \\
\hline 9 & $\begin{array}{l}\text { Materials \& Processes, Materials, } \\
\text { Advanced Engineering Materials, } \\
\text { Materials For The Polymer Industry (E), }\end{array}$ & Engineering Materials and Forming Technology \\
\hline 10 & $\begin{array}{l}\text { Energy Systems \& Thermo-Fluids (2.1-- } \\
\text { 3.2), } \\
\text { Applied Thermo-Fluids, Heat Transfer }\end{array}$ & \\
\hline 11 & $\begin{array}{l}\text { Integrated Energy Systems(E), } \\
\text { Energy \& Environmental } \\
\text { Management(E), }\end{array}$ & New Energy Machine and Equipment(E) \\
\hline 12 & $\begin{array}{l}\text { Statistical Process Evaluation and } \\
\text { Control, } \\
\text { Quality \& Project Managements 3, } \\
\text { Manufacturing System and Organization } \\
\text { Management } \\
\text { Lean \& Six Sigma(E), Operations } \\
\text { Management }\end{array}$ & Machinery Industry Enterprise Management(E) \\
\hline 13 & $\begin{array}{l}\text { Computer Aided Engineering Design } \\
\text { \&Analysis(4.1\&4.2) }\end{array}$ & $\begin{array}{l}\text { Mathematical Modeling, } \\
\text { Mechanical CAD and CAM, } \\
\text { Modern Design Methods(E), }\end{array}$ \\
\hline 14 & Final Project & Final Internship, Final Project \\
\hline
\end{tabular}

In module 8, control and automation, manufacturing automation, and industrial control in the AIT course mainly involve engineering control, PLC, robotics, industrial communication and network and automation technology, all of which are major technologies for Made in China 2025 plan. Those contents in ECUT are seriously inadequate relatively, and there is a lack of practice related to control and automation in ECUT. In module 9, advanced engineering materials and polymer materials are embodied in the AIT curriculum, while ECUT has no such content. Module 10 is the knowledge of energy system and thermal fluid technology. This content of AIT is 
extensive, and there is no content about that in ECUT. And the importance and necessity of thermal fluid technology are highlighted in the ME standards for International Engineering. Therefore, it is necessary to add curriculum of thermal fluid in ECUT. In module 11, the AIT curriculum includes integrated energy system and energy and environmental management technology, while only basic knowledge of new energy equipment and technology learnt in ECUT. And the ME graduates trained by ECUT would lack of skills of energy environment system and management. In module 12, courses like production control and evaluation, quality and project management, manufacturing systems and organization management, lean production and Six Sigma and process management are included in AIT ME curriculum. On the contrary, ECUT only contains machinery industry management in this module. So there is a serious shortage of knowledge and skills in production quality process, economic cost, six sigma and quality and project management. In module 13, the ME curriculum of AIT mainly includes computer aided design modeling and finite element analysis. Relatively, the finite element analysis part is not enough in ECUT ME curriculum. In the final module 14, there is little difference between AIT and ECUT, including enterprise internship and final design.

\section{The Knowledge and Skills Gained}

In order to further analyze the similarities and differences of the ME curriculum system between AIT and ECUT, and to provide a reliable suggestion for the curriculum reform of ME in China, the author conducted a questionnaire survey and Analysis on the results of knowledge and skills gained by senior graduates from AIT and ECUT during the academic visit in AIT. The questionnaire is based on the research results of the mechanical engineers' future by American Society of Mechanical Engineers (ASME) [7]. The questionnaire mainly investigated the condition of knowledge and skills gained by senior students from the two institutes. And 30 (30\%) questionnaire feedbacks from senior ECUT graduates and 12 (100\%) from AIT were received finally.

At present, English is the most widely accepted and used international language. Ireland, as a European country with the official language of English, does not have a compulsory course in most Irish colleges and universities. In Figure 1, 90\% of the ME graduates of AIT have not learnt one foreign language, and $100 \%$ of the senior ME graduates of ECUT have learnt a foreign language. English as a compulsory curriculum in ECUT would benefit future mechanical engineers graduated from ECUT in international cooperation and competition.

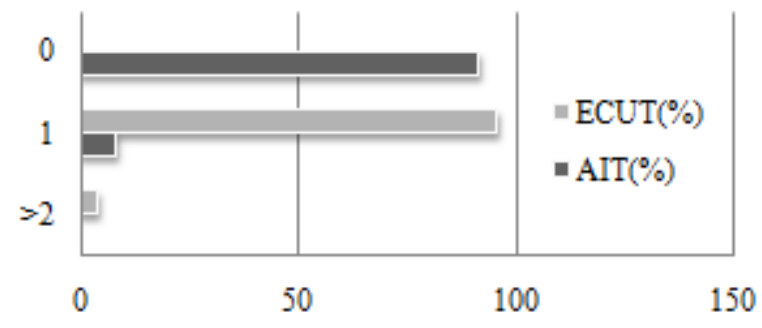

Figure 1 The number of foreign languages learnt

In the new era, the ability of computer programming and automatic programming will become more and more important to future mechanical engineers. Figure 2 shows that nearly $100 \%$ of ME senior students of ECUT have mastered C programming language, and the rest of the programming tools have been barely mastered. Meanwhile, a small number of AIT senior students are familiar with C language, and a small number of AIT senior students have automatic programming languages skills. The above confirmed the setting of programming ability courses in ME curriculum of ECUT and AIT. ME curriculum of ECUT have C programming language design course, but lack of automation courses. While, AIT has not offered the $\mathrm{C}$ programming language design course, but has involved automatic control programming knowledge in automation courses. 


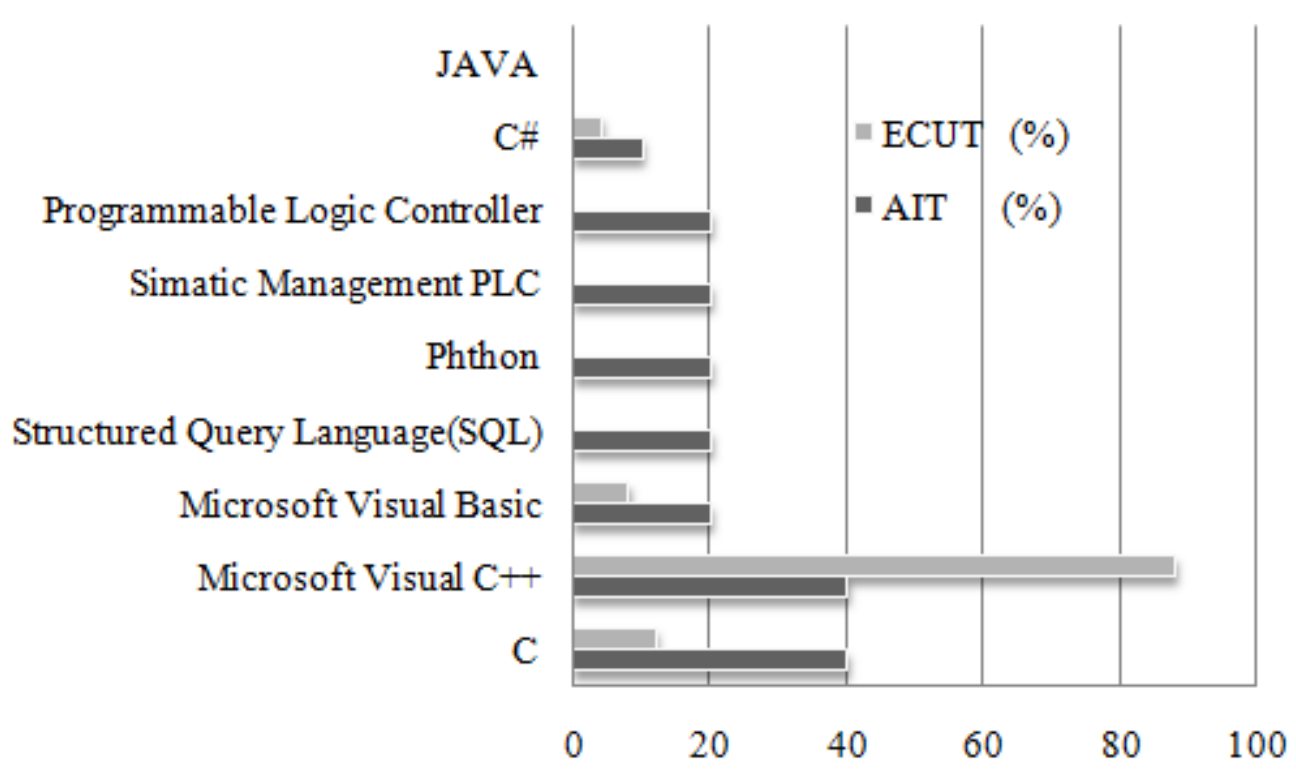

Figure 2 Programming languages used

Using of ME design and calculation software is one of the most important technical capabilities of mechanical engineers nowadays. The common ME software includes AutoCAD, 3D modeling software, engineering calculation software, and finite element analysis software. From Figure 3, it indicates that ME senior students from both AIT and ECUT are proficient in using Creo Parametric, Auto CAD. And AIT seniors are skilled in using Solidworks tools and Matlab, while ECUT Seniors is more proficient in Master CAM. The ME graduates from both AIT and ECUT are not good at using the finite element analysis and calculation software ANSYS.

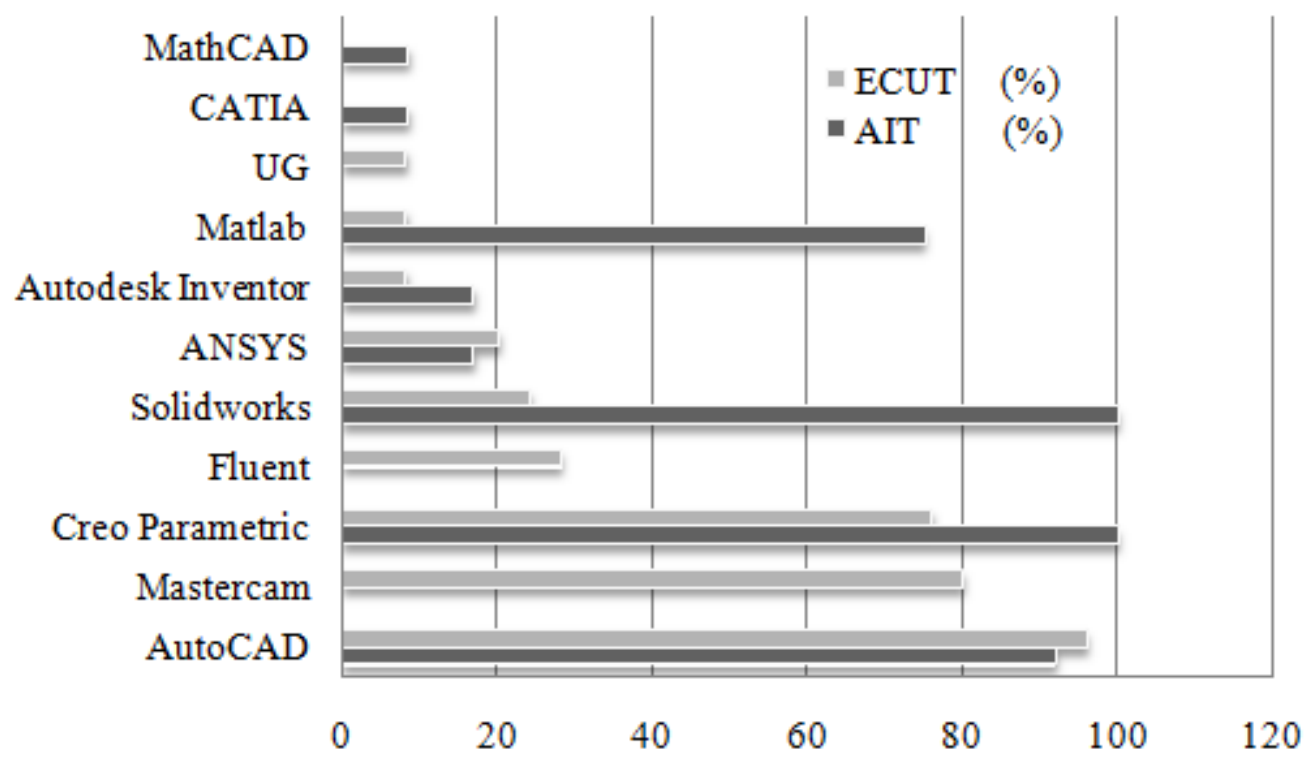

Figure 3 Engineering software used

Figure 4 is a comparison of knowledge and skills gained by ME senior students between AIT and ECUT. Firstly, in the field of energy, nanotechnology, biotech and thermal fluid analysis, the knowledge and skills gained by ME graduates of AIT is obviously better than that of ME graduates of ECUT. This can be confirmed by the ME curriculum system of AIT and ECUT. The ME curriculum of AIT includes energy, thermo-fluids, fluids mechanics and advanced engineering materials and so on, while the curriculum system of ECUT is seriously lacking in such kind of courses. Secondly, on the aspect of production and process management and project management, the learning outcomes of ME graduates of AIT are better than that of ECUT. According to table 1, the ME curriculum of AIT includes 4 courses on production, quality, process and project 
management, while ECUT has only one industrial enterprise management course, and lacks of production and quality management courses. Thirdly, from the use of modern equipment, academic paper report writing, speech, communication, determination and analysis of engineering problems and other skills, it is found that the practical experience of AIT ME graduates is more than that of ECUT ME graduates. It can be inferred that there are more practical classes in the ME courses of AIT, and that is good reference in ME curriculum reform of ECUT. Fourthly, in terms of engineering codes and standards, AIT ME graduates are better than ECUT ME graduates. Fifthly, the ability of ME graduates of AIT are better than that of ECUT ME graduates on the multidisciplinary aspects, which can be confirmed from the curriculum comparison between AIT and ECUT. The ME curriculum of AIT does not only involve traditional ME course, but also contain automation, advanced materials, energy, thermo-fluids and production and project management. Though the ME curriculum of ECUT contains courses on the field of energy, industrial management and control, but it is not enough and does not even involve a number of disciplines.

On the whole, ME graduates of AIT obtained more knowledge and skills in the four-year study of university than that of ECUT. To a certain extent, the ME curriculum system of AIT has important references for the reform of ME curriculum system of ECUT.

Ability to use new engineering technology(such as energy,nano, bio technology)

Ability to use advanced design and analysis technology(such as thermal and fluids, etc..

Ability to design a system, component, or process to meet desired need for mechnical engineering

Ability to understand contemporary issues

Ability to use modem hardware tools(how devices are made and work) and technology

Ability to design and conduct experiments,nanlyze and interpret data

Ability to manage process and operation

Ability to write technical academica paper or report

Ability to present speech

Ability to communicate effectively

Ability to understand engineering codes and standards

Ability to manage engineering project

Ability to use modem engineer software tools necessary for engineering practice

Ability to identify, formulate and solves engineering problems

Ability to function on multi-disciplinary teams

$$
=\operatorname{ECUT}(\%) \quad-\operatorname{AIT}(\%)
$$

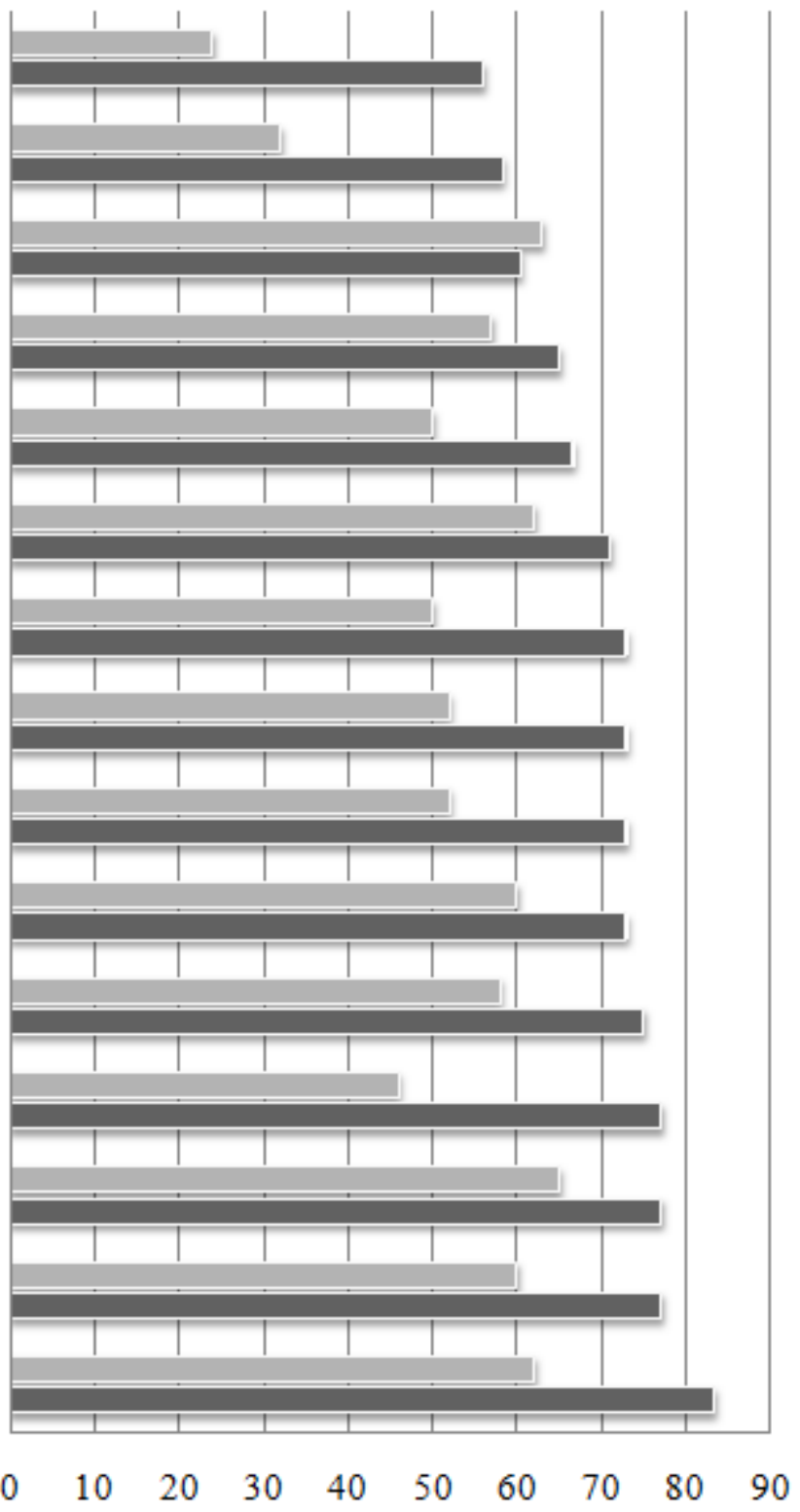

Figure 4 Average scores of ME knowledge and skills learnt by ME senior students 


\section{Exploration on the Reformation of ME Curriculum System of ECUT}

The ME major of ECUT began in the early twenty-first Century, and would be still in the period of drawing on the experience of colleges and universities in China, but a good stage of development could be seen. The "3+1 cooperative program" in ME major between ECUT and AIT is being carried out successfully. Drawing on the advanced ME education experience of AIT, and combining with the new requirements of Made in China 2025 strategy in the new period to reform the ME curriculum of ECUT is the method of this paper. This reform would promote the development of "3+1cooperative program" between AIT and ECUT, on the other hand, it would be a reference for other colleges or universities to reform its ME curriculum in China or other developing countries. The specific reform measures are as follows.

Firstly, the comprehensive education courses such as the humanities, the history, the ideological and moral law, the Marx theory, the military theory, physical training and so on are compulsory courses in High education according to the education department of China, so it remains unchanged. Secondly, in the practice of mechanical design foundation, the theory of machinery and machinery design courses is changed to the mechanical comprehensive innovation design and practice course. This comprehensive practical course will be on the second and third year as the form of student team, and it focuses on training the comprehensive practical ability of researching, designing, processing, control and testing. Thirdly, In order to meet the needs of manufacturing intelligence in the "Made in China 2025" strategy[8], the contents of intelligent sensing and testing would be increased in ME curriculum. Fourthly, in the aspects of language, speech, computer using and programming skills, the ME curriculum of ECUT has a positive evaluation. but the ME graduates of ECUT are relatively not as good as AIT graduates in communication and academic reports aspects according to above investigation, so the reading report course is changed to project exchange and report course which will be a part of the mechanical comprehensive innovation design and practice course, so students' practical ability of academic reports and speeches would be cultivated. Fifthly, as there are too much content on manufacturing technology, numerical control technology and mechanical CAD and CAM, practical training like manufacturing process and numerical control training are integrated into manufacturing technology and $\mathrm{CN}$ technology courses to make it organic with theory course in order to improve the learning and practice quality. At the same time, the advanced manufacturing technology course is added to make up the knowledge and skills in precision manufacturing, high energy beam machining, 3D printing, industrial robots, flexible manufacturing and intelligent manufacturing. Sixthly, in the field of control and automation, the principle and application of SCM, electrical control and PLC application and industrial network technology are added, which is to enhance the knowledge and skills of ME graduates of ECUT in control and automation and industrial communication network. Seventhly, the college chemistry and advanced engineering materials courses are added in this curriculum reform to enrich the students' knowledge on high chemistry, polymer materials, functional materials, biomedical materials and nano-materials. In addition, this will be good for the integration between ECUT and AIT in the ME major. Eighthly, in the field of thermo-fluids discipline, thermal engineering, fluid mechanics and computational fluid mechanics has been added to make up for the gap of ECUT ME major in knowledge of thermo-fluids. Ninthly, the ME curriculums of most colleges or universities in China are lack of courses on processing and production, quality and project management, and environmental management. So it is necessary to add courses on Process and management, quality and project management, and energy systems and project management to develop other necessary knowledge and skills of mechanical engineers. Lastly, to make sure the total credits of the ME curriculum of ECUT to be the same, some of the curriculum modules would be increased or decreased on the credits, and the finite element analysis and practice have been strengthened in the optimization design. The other parts of the ME curriculum system of ECUT remain the same basically. 


\section{Conclusion}

With the rapid development of industry in various countries, the knowledge and skills gained by graduates from old curriculum in colleges or universities could ever not meet the new national developing plan. Based on the new needs of the manufacturing strategy of China and the " $3+1$ cooperation project" between AIT and ECUT, this research conducts the ME curriculum reform of ECUT. Firstly, the ME curriculums between AIT and ECUT were compared, and it could be found the ME curriculum of AIT involve a lot of comprehensive and advanced content. Secondly, the questionnaire survey based on the investigation of the key knowledge and technology needed by mechanical engineers in the next decade by ASME was carried out to find the deference of knowledge and skills gained between AIT and ECUT. And the results of the survey indicates that the knowledge and skills gained by ME graduates of AIT are more than ECUT ME graduates on aspects of automation, advanced materials, thermo-fluids, modern equipment, engineering code and standards, processing and quality management, project managements and academic reports and speeches. Finally, this paper has carried on the reform of the ME curriculum system of ECUT. One of the important reform measures is to add or enhance contents on control and automation, thermofluids, processing and quality management, project managements, engineering code and standards, advanced engineering materials(biology, nano-materials, polymers, etc.), advanced manufacturing technology(3D printing), industrial network technology, finite element analysis and application, intelligent sensing, project reports and so on. And one of the important innovations of the reform is the development of mechanical comprehensive innovation design and practice course by integrating several practical courses. The new practical course which opened in the $4^{\text {th }}-7^{\text {th }}$ semester integrates researching, design plan, detail design, processing, manufacturing, assembly and debugging, project report and exchange, team work skills and so on. To promote the combination of learning and practice, some of the independent professional practices are integrated into the theory course.

This research would be a reference for developing ME curriculum for undergraduate programs in some developing countries or even across the world. The reformation based on national manufacturing developing plan will benefit graduates to be qualified for recent and future's rapidly changing manufacturing industry in China or even worldwide.

\section{Acknowledgements}

This work was financially supported by the Education Science 13th Five-Year plan project of Jiangxi province of China, grant number 17ZD026 for which the authors are grateful to the donor.

\section{References}

[1] Tuoyu Li, Fei Li, and Guodong Lu. 2015. “On Improving the Quality of Engineering Tecchnology Talents Cultivation in Terms of The 'Made in China 2025' Strategy,(In Chinese), ”Research in Higher Education of Engineering, 6: 18-23.

[2] Research Group of the "Made in China 2025" Plan and the Cultivation of Engineering Technology Talents. 2015. “The 'Made in China 2025' Plan and the Cultivation of Engineering Technology Talant, (In Chinese) ” Research in Higher Education of Engineering, 6: 6-10.

[3] Xiaoping Liu, Yu Lan. 2017. “A Brief Discussion on Higher Education Orienting Towards "Internet Plus" and 'Made in China 2025',(In Chinese)” Education Teaching Forum, 4: 1-4.

[4] Xiaoming Xu, Hai Zhou. 2017. “The Reconstruction of the Training System of Mechanical Specialty in Local Undergraduate Colleges and Universities, (In Chinese)" Education Modernization, 48: 3-5.

[5] Fenglin Han, Hongzhi Yan. 2016. “A Discussion on Construction of Courses System for Mechanical Manufacturing Major Oriented to Requirements of Industy 4.0, (In Chinese)" China Educational Technology \& Equipment, 2: 84-89. 
[6] D. Scott, A. Kirkpatrick, and E. Ervin. 2012. “ASME Vision 2030: Helping to Inform Mechanical Engineering Education,” 41st ASEE/IEEE Frontiers in Education Conference, Rapid City, SD, October 15,2012, pp. T1J-1-T1J-6.

[7] American Society of Mechanical Engineers. "State of Mechanical Engineering Today and Beyond,” [EB/OL]. 2012-08-20(2) [2017.09.26]. https://www.asme.org/getmedia/752441b6-d3354d93-9722-de8dc47321de/State-of-Mechanical-Engineering-Today-and-Beyond.aspx.

[8] Ji Zhou. 2015. “Intelligent Manufacturing Main Direction of 'Made in China 2025', (In Chinese)”Journal of China Mechanical Engineering of China, 17: 2273-2284. 